\title{
Information Structure and the Status of NP in Russian*
}

\author{
Dina Brun \\ New Haven \\ dina.brun@yale.edu
}

\section{Introduction}

In his 1995 monograph, Apresyan suggests that it would be extremely interesting to investigate the means of expressing the definiteness/indefiniteness opposition in languages that do not have articles (Volume 1, p. 258, fn. 3). In this paper, I will attempt to find possible correlations between the organization of discourse and the positions in which the (in)definite nominals may appear within a sentence of Russian. I will examine the information structure of Russian sentences and, based on the previous analyses, provide a new account of their organization with respect to information packaging. I will then look at various nominal elements contained in certain parts of a sentence and arrive at a system describing the distribution of NPs in Russian with respect to the information structure.

The ultimate goal of this paper is to establish and motivate a system of correlations between various types of NPs and functions of information structure. This goal will be achieved by determining which characteristic of a NP may serve as a criterion allowing to provide a one-to-one mapping.

\section{Information structure of Russian}

In this section, I discuss the organization of Russian sentences with respect to information structure. I will consider the main points of previous research and propose a new analysis based on Vallduví's approach to the structure of discourse (1992). I will provide a brief account of both the neutral and emphatic sentences concentrating on the role word order plays in both contexts.'

\subsection{Traditional Analyses}

The two major traditional approaches to the problem of sentential word orders and discourse functions in Russian and other Slavic languages are Functional Sentence Perspective (FSP) (Mathesius 1964, Adamec 1966, Isačenko 1966, Sgall 1972, Hajičová

\footnotetext{
* The paper is submitted to a special issue of "Theoretical Linguistics", edited by Klaus von Heusinger and Kerstin Schwabe

1 In some important sources (e.g., Yokoyama 1986; Krylova \& Khavronina 1988; King 1995) neutral sentences are referred to as non-emotive, while emphatic sentences are called emotive. In this paper, I will use the traditional terminology, namely, the neutral vs. emphatic opposition.
} 
1974, Krylova \& Khavronina 1988, inter al.) and Topic Focus Articulation (TFA) (Firbas 1964, Rochemont 1986, Yokoyama 1986, inter al.). According to these analyses, a Russian sentence consists of two parts: a theme and a rheme (FSP) or a topic and a focus (TFA). The first part of the sentence constitutes given information while the second part constitutes new information. Within these parts, the material may also be arranged along a hierarchy known as Communicative Dynamism, a notion introduced by Firbas (1966): new information is more important and, therefore, more dynamic than older information (see Sgall, Hajičová, \& Panevová 1986 for an overview).

However, problems with the two-way division were recognized. First, under the traditional approach, all material in a sentence must fall into the theme or the rheme. Rheme would contain the focused material and, therefore, theme would have to comprise the rest of the sentence including both the topic(s) and the discourse-neutral material. In particular, the role of non-focused verb in the division of the sentence was questioned. Some additional function should be assigned to such a verb, which does not seem to fit the definition of focus (or rheme) and, at the same time, may not be considered part of topicalized (or thematic) material. ${ }^{2}$ To solve this problem, Firbas (1965) proposed that the verb behaved as a transition between the theme and the rheme. Therefore, the new sentence structure consisted of three parts: theme, transition and rheme.

It was later observed that non-focused verbs were not the only constituents needing a separate treatment. In fact, the issues connected with the so-called Complex Theme were discussed in Krylova \& Khavronina (1988). The authors showed that within the thematic part of a sentence, independent parts could also be found. Along with multiple topics, perfectly possible in Russian, they observed the presence of material not fitting the description of topic as the items of immediate interest to both speakers. The non-topic material found in the theme was labeled discourse-neutral material.

Hence, we have two separate solutions with respect to the informational articulation of the sentence material not fitting into the previously assumed dichotomy. Combining these two ideas, i.e. allowing sentential elements other than the verb to appear in the transition, or allowing the non-focused verb to be treated as discourse neutral, we can get a three-way division into topic, discourse-neutral material, and focus (cf. King 1995). This trinomial articulation is reminiscent of Vallduví's (1992) system of discourse. His sentence consists of a mandatory focus, and the optional ground material responsible for the appropriate entry of information into the hearer's knowledge-store. The ground, in turn, is divided into two parts: the link and the tail. The link's task is to direct the hearer to a given address in the hearer's knowledge-store under which the information conveyed by the sentence should be

2 The claim that non-focused verb may not be considered part of the focus seems to some extent valid to me. However, Vallduví (1992), providing the bracketed structures for his examples, always includes such verbs into what he refers to as "focus." In fact, the answer to the problem whether intonationally non-focused verbs should be considered foci depends on the context. Consider the two examples below (the responses are from Vallduví, questions are mine):

(i) Q: What did the boss hate?

A: The boss hated [F the salty broccoli QUICHE].

(ii) Q: What did the boss think about the food?

A: The boss [F hated the salty broccoli QUICHE]. 
entered. The link must be sentence-initial and may be multiple. Finally, the tail is an element acting as a signal to indicate how the information encoded within the sentence must be entered under a given address. The position of tail is not universally constant: it is a nonfocal, non-link part of the sentence.

\section{Types of Speech in Russian}

Let us now examine whether the proposed trinomial articulation of information is a solution for the discourse organization of the Russian sentence. Two types of sentences will be considered: neutral and emphatic. As argued by Yokoyama (1986), the difference between these two types of speech is one of sentence stress: neutral sentences have no sentence stress, while emphatic sentences have it. I will show that the presence of sentence stress plays a crucial role in discourse organization of Russian sentences, their possible structures and interpretations.

\subsection{Discourse-neutral speech}

In utterances characterized by neutral intonation and the lack of sentence stress, strict connection between word order and discourse functions is observed. Such sentences are organized along a scale from given to new information and topics $(\mathrm{T})$ always precede foci $(\mathrm{F})$, while the discourse-neutral information (NI) intervenes. Below are examples of the various patterns of discourse organization:

a. Q: Kto igraet $\mathrm{v}$ pryatki?

who plays in hide-and-seek

'Who is playing hide-and-seek?'
A: [NI Igrajut] [F deti].
$\mathrm{NI}>\mathrm{F}$
play children
\# [F Deti] [NI igrajut] .
$\# \mathrm{~F}>\mathrm{NI}$
'Children are playing hide-and-seek.'

b. Q: Čto delajut deti?

what are-doing children?

'What are the children doing?'

A: [T Deti] [F igrajut $v$ pryatki].

children play in hide-and-seek

\# [F Igrajut $\mathrm{v}$ pryatki] [T deti].

'The children play hide-and-seek.'

$\mathrm{T}>\mathrm{F}$

$\# \mathrm{~F}>\mathrm{T}$

c. Q: Kto šil eto plat'je?

who sewed this dress

'Who sewed this dress?' 
A: [T Eto plat'je] [NI šila mne] [F portnixa]. this dress sewed me-DAT tailor \#[F Portnixa] [NI šila mne] [T eto plat'je]. \#[NI Šila mne] [T eto plat'je] [F portnixa]. \#[F Portnixa] [T eto plat'je] [Ni šila mne]. 'A tailor sewed this dress for me.,
$\mathrm{T}>\mathrm{NI}>\mathrm{F}$

$\mathrm{HF}>\mathrm{NI}>\mathrm{T}$

$\# \mathrm{NI}>\mathrm{T}>\mathrm{F}$

$\mathrm{\# F}>\mathrm{T}>\mathrm{NI}$

The word orders exemplified in (1a-c) show that the only order of discourse functions possible for a neutral intonation sentence of Russian is Topic(s) > Neutral Information > Focus. Intuitively, while topic and neutral information are optional, focus, being the source of new information, must be present in every sentence:

$$
\begin{aligned}
& \text { Q: Kto činit igruški? } \\
& \text { who is-fixing (some) toys-ACC } \\
& \text { 'Who is fixing toys?' }
\end{aligned}
$$

A: [F Mal'čik]./ \#[T Igruški]./ \#[NI Činit] [T igruški].
(a) boy
(the) toys
is-fixing toys

Thus, I conclude that while word order is relatively free in Russian and is not responsible for grammatical relations in this language, it is fixed with respect to the organization of discourse in the sentences with neutral intonation contour (cf. Junghanns \& Zybatow 1995, Brun 2000, inter al.)

\subsection{Emphatic speech}

In sentences with emphatic intonation, the placement of sentence stress interacts with the discourse interpretation of the sentence. In such sentences, the word order is less constrained than in non-emphatic sentences: the focus is indicated not by means of the linear order of constituents but is marked by stress or intonation contour. ${ }^{4}$ Hence, the location of a focused constituent does not necessarily coincide with the right edge of the sentence, as is the case with the intonationally neutral sentences. In fact, this word order is judged as marginal:

$$
\begin{aligned}
& \text { a. Ivan [F VODKU] vypil. } \\
& \text { Ivan VODKA drank } \\
& \text { b. [F VODKU] Ivan vypil. }
\end{aligned}
$$

3 I provide only three examples of impossible word orders with the intended meaning. However, all other structurally possible constructions are also unacceptable with the necessary interpretation and the indicated correct variant is the only possible for this context.

4 According to Russian linguistic literature, Russian has a total of six intonation contours (IK). In this paper, I will only talk about the relevant patterns IKI (neutral intonation) and IK2 (roughly, stressed focus intonations.) For detailed discussion of Russian intonation system, see Bryzgunova (1971, 1981); Yokoyama (1986), Krylova \& Khavronina (1988) among others. 


\section{c. ?Ivan vypil [F VODKU]. \\ 'Ivan drank VODKA.'}

Examples in (3) indicate that the stressed focus may be either sentence-initial or sentencemedial, while the judgement for sentence-final occurrence is degrading ( $3 \mathrm{c})$. The following rule explains the mechanisms of assigning sentence focus:

\section{Focus Rule}

Intonational focus $\left(\mathrm{F}_{\mathrm{c}}\right)$ overrides focus marked by word order effects unless the two coincide. In the latter case, the double-marked sentence receives degrading status due to Economy (Chomsky 1991, 1992).

So far, I have established the account of structural and intonational foci assignment. Now I would like to consider the status and meaning of intonational focus in Russian and determine the differences between the two types of foci in this language. Recall that sentence-final focus in Russian (and other languages) was described as a subpart of the sentence where the information is concentrated and, more importantly, as the location of new information. However, the role of intonational focus is distinct from this definition. As claimed by King (1995, following Kiss' 1993 analysis of Hungarian intonational foci), stressed focus constitutes the category of contrastive foci. In other words, the information contained in such foci is not exactly discourse-new, but discourse-present as an implicature (e.g., within a set of related items) and, therefore, is recoverable (see Prince 1981 for discussion of the notions of givenness.) Consider the following examples:

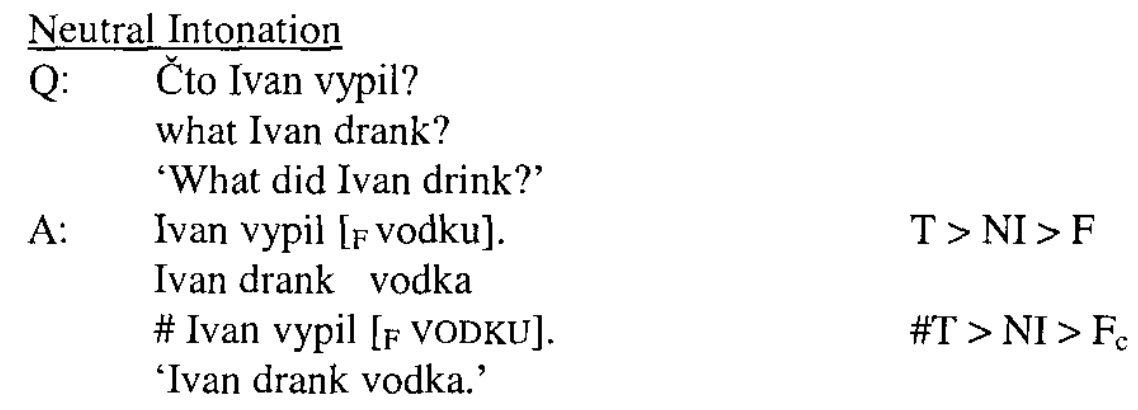

(6) Emphatic Intonation

Q: Ivan vypil vodu?

Ivan drank water

'Has Ivan drunk water?'

A: (Net)[F VODKU] Ivan vypil.

(No) vodka Ivan drank

(Net) Ivan [F VODKU] vypil.

$\mathrm{F}_{\mathrm{c}}>\mathrm{T}>\mathrm{NI}$

\#Ivan vypil [F VODKU].

'No, it was VODKA that Ivan drank.'

$\mathrm{T}>\mathrm{F}_{\mathrm{c}}>\mathrm{NI}$

$\# \mathrm{~T}>\mathrm{NI}>\mathrm{F}_{\mathrm{c}}$ 
These data demonstrate that the intonational focus may not be used in the context requiring new information as the answer, or information from an open set (Kiss 1993). The intonationally focused material must belong to a closed set of members. Hence, the structurally grammatical but intonationally marked counterpart in (5) is ruled out. The neutral intonational focus, on the contrary, may only be associated with new, nonpredictable information and may not be accepted as a contrastive answer as seen in (6).

\subsection{Implications for the Articulation}

In section 3.1 I showed that while neutral intonation sentences exhibit invariable order among the discourse functions (Topic(s) $>$ Neutral Information $>$ Focus), this is not the case for emphatic utterances. In fact, the latter allow for relatively free order of constituents. We have seen that the stressed focus may appear in any position within a sentence, thus moving the rest of material around. Allowing focus to appear sentence-initially or sentencemedially, the system must account for other possible deviations from the standard order. For example, the apparent position of discourse-neutral material may now be distinct: discourse-neutral material does not necessarily occur between topic and focus, but may actually appear sentence-finally. Also, focus may precede topic rather than always follow it. However, it is never the case that discourse neutral material precedes the topic:

$\begin{array}{lll}\text { Q: } & \text { Deti lyubyat ovošči? } & \\ & \begin{array}{l}\text { children like vegetables } \\ \text { 'Do children like vegetables?' }\end{array} & \\ \text { A: } & \text { [F POMIDORY] [T deti] [NI lyubyat]! } & \mathrm{F}_{\mathrm{c}}>\mathrm{T}>\mathrm{NI} \\ & \text { tomatoes children like } & \\ & \text { [T Deti] [F POMIDORY] [NI lyubyat]! } & \mathrm{T}>\mathrm{F}_{\mathrm{c}}>\mathrm{NI} \\ & \text { \#[F POMIDORY] [NI lyubyat] [T deti]! } & \# \mathrm{~F}_{\mathrm{c}}>\mathrm{NI}>\mathrm{T} \\ & \text { \#[NI Lyubyat] [F POMIDORY] [T deti]! } & \text { \# NI }>\mathrm{F}_{\mathrm{c}}>\mathrm{T} \\ & \text { 'The/Gen children like TOMATOES!' } & \end{array}$

Let us now see whether the possible orders of discourse elements contradict the idea of Communicative Dynamism. The characteristics of intonational (or contrastive) focus described in section 3.2 provide grounds for concluding that this type of focus is actually of a topic nature. Recall that it does not introduce new information as is required of a real focus, but instead refers to inferable information. Hence, topic and contrastive focus do not necessarily have to occur in some restricted order with respect to one another. As to the elements representing discourse-neutral material, as before, they always follow older, given, or inferable information and precede new information, since the contrastive focus may not appear in a sentence-final position. Therefore, the Communicative Dynamism hierarchy is preserved both with structural and intonational foci.

Recall now that in Vallduvi's framework (1992) the focus was the only ineludible part of a sentence. This claim seems to be logically verifiable: sentence is a unit of information and focus is the part of the sentence providing new information. However, considering contrastive foci regular topics would permit focusless sentences. To avoid this problem, I 
propose that contrastive focus be considered as hybrid element, topic-focus. This constituent would be both the source of new information and the connector to the previous context. Such a proposal does not contradict Vallduví's definitions. In fact, topics (or links) may be multiple (in Russian as well as other languages): focus-topic and topics may cooccur in one sentence. They must be sentence-initial: we know from the order facts that this prediction is borne out. Finally, the position of discourse neutral material (or tail) is not the same universally: in Russian, it may either precede the focus, or occur sentence-finally.

\section{Russian NP}

Russian is a language without obligatory overt determiners indicating (in)definiteness of noun phrases in such languages as English or French. The distinction between definite and indefinite nominals is an important element of discourse and, therefore, should be universally present in any natural language. Hence, the apparent difference among languages is not in the presence or absence of the definite/indefinite distinction but rather in the ways this distinction is expressed. In this section, I will consider several such mechanisms that will later be used in the analysis to check whether a particular type of NP may appear in a certain position within a sentence.

\subsection{Means of expressing (in)definiteness}

Russian distinguishes among several ways of expressing (in)definiteness of nominal phrases: lexical, non-lexical, and syntactic. All three types of distinction will be explained and exemplified in the following subsections. One important characteristic common to all of these mechanisms should be mentioned first. While in languages with overt articles the distinction is usually two-way (i.e. a NP may be either definite or indefinite), in Russian there exists an additional third status of NPs: unmarked NPs. The NPs of this type are ambiguous with respect to (in)definiteness and the value is determined only from the context.

\subsubsection{Lexical Distinction}

The lexical distinction is provided by means of certain overt lexical items placed in front of the noun phrase in question. These lexical elements may be viewed as determiners. The function of determiners is usually performed by demonstrative pronouns eto (this), to (that) or possessive pronouns moj (my), tvoi (your), ih (their), etc. Another group of lexical elements used to distinguish between the indefinite and definite interpretation is the class of attributive pronouns, e.g., každyj/vsyakij (everyone/anyone), nečto/čto-nibud' (something/ anything). In these pairs, the left member is unmarked while the right member contributes to the indefinite interpretation of the NP. The following examples illustrate how these pronouns affect the interpretation of the NPs they modify: 


\section{Dina Brun}
a. Cvety vyanut.
flowers wither-PRES
'(The/Gen/ $\varnothing)$ flowers are withering.'
b. Eti/te/moi cvety vyanut.
these/that/my flowers wither- PRES
'These/that/my flowers are withering.'
c. Vsyakie/kakie-to cvety vyanut.
some/any flowers wither- PRES
'Flowers are withering.'

The sentence in example (8a) when placed out of context allows for both interpretations: the NP cvety 'flowers' may be considered either indefinite or definite. Example (8b), on the other hand, represents the only possible definite interpretation: similarly to English, the distributive pronouns act as definite articles in Russian. Finally, (8c) is an example of an unambiguous indefinite interpretation. In addition, although the NP in (8a) is treated as unmarked, some preference towards the indefinite reading will appear once the NP is placed after the verb. I will return to the discussion of the effects the word order has on the interpretation of NPs Jater.

\subsubsection{Non-lexical Distinction}

(In)definiteness may also be expressed non-lexically. One of the ways of non-lexical distinction is through the absence or presence of agreement between a noun and modifying adjective: agreeing adjectives denote indefiniteness, while non-agreeing (i.e. genitivemarked or possessive nouns) are unmarked for (in)definiteness:
a. Za dver'ju slyšalsya ženskij golos.
behind door was-heard woman-MASC.SG.NOM. voice-MASC.SG.NOM. 'There was a woman's voice heard from behind the door.'
b. Za dver'ju slyšalsya golos ženščiny.
behind door was-heard voice-MASC.SG.NOM. woman-FEM.SG.GEN.
'The voice of a/the woman was heard from behind the door.'

The factor affecting the interpretation of the NPs in question is within the NP itself. In section 4.2 , I will consider the effects of word order changes with respect to the position this NP occupies in the sentence.

Another interesting way of expressing definiteness in Russian is through verb morphology. In particular, perfectivizing verb prefixes denoting the completion of an event or action correlate with definiteness. Note that these morphemes do not correspond to the aspect dichotomy realized on Russian verbs. In other words, a verb may carry the prefix do, describing event completion, and at the same time denote an imperfective event (e.g., dopisat'-PERF,INF 'to have finished writing' vs. dopisyvat'-IMPERF,INF 'to be finishing writing'). The following sentences illustrate the correlation between the verb denoting the achievement of a result and the definiteness of the nominal argument: 

a. On napisal pis'mo.
he has-written-PERF letter
'He has written a/?the letter.'
b. On dopisal pis'mo.
he has-written-to-the-end-PERF letter
'He has written the letter to the end.'
c. On dopisyval
pis'mo.
he was-writing-to-the-end-IMPERF letter
'He was finishing writing the letter.'

The example in (10a) contains the perfective verb denoting a completed activity (i.e. the verb has an event focus) and the argument is unmarked. The verbs in examples (10b\&c), in turn, have the result-focus reading. Consequently, the direct object NP is unambiguously interpreted as definite.

\subsubsection{Word order distinction}

Finally, the last method of expressing (in)definiteness of a noun phrase is by means of the word order (or the order of constituents) within a sentence. The correct generalization of such effects for Russian is that the overt fronting of constituents correlates with definiteness. In the following examples, we will consider the interpretation of the nominal adjunct po doroge 'on (the) road':

(11) a. On prošel neskol'ko mil' po doroge.

he walked several miles on road

'He walked several miles on a road.'

b. On prošel po doroge neskol'ko mil'. he walked on road several miles

'He walked several miles on a/the road.'

c. Po doroge on prošel neskol'ko mil'. on road he walked several miles 'It was on the road that he walked several miles.'

A similar observation was made by Chvany (1973) and King (1995). These authors illustrate the effects of fronting by changing the position of the subject and adjunct:

(12) a. Na stole stojala lampa.

on desk stood lamp

'There was a lamp on the desk./On the desk was/stood a lamp.'

b. Lampa stojala na stole.

lamp stood on desk

'The lamp was on a/the desk.'

(Chvany1973:266; King 1995:78) 
These examples show that the closer the NP appears to the front of a sentence, the likelier its definite reading is. In addition, we may notice that what seems to matter is the position of the NP with respect to the verb: preverbal position provides for the definite reading:

(13) Na stole lampa stojala.

on desk lamp stood

The lamp was on the desk.

In fact, once the adjunct (11b\&12a) or the subject (11b) and, crucially, both NPs (13) appear before the verb, the interpretation of the NPs disambiguates and becomes definite.

\subsection{Interactions}

In the preceding section, we observed that such factors as the presence of certain lexical items (i.e. words or morphemes), lack or presence of agreement, and differences in word order influence the interpretation of NPs in Russian. However, so far we concentrated on the effects of these factors independently, without looking at possible consequences of their interaction. Let us now examine whether the syntactic operation of word order change affects other means of definite/indefinite distinction.

We will begin with the lexical distinction. Recall that the possibilities were limited to the unmarked vs. definite opposition in the case of distributive pronouns. It was claimed that the preferred interpretation for the unmarked NP is indefinite if the NP appears after the verb, whereas the preverbal position competes between generic and definite interpretations:
a. Vyanut cvety.
wither-PRES flowers
'??The/ $\varnothing$ flowers are withering.'
b. Cvety vyanut.
flowers wither- PRES
'The/Gen flowers are withering.'

However, when the noun is modified by one of the distributive pronouns, the interpretation is always definite and the actual position of the NP in the sentence is irrelevant:
Vyanut eti/te cvety.
wither- PRES these/that flowers
'These/that flowers are withering.'

If we turn to the non-lexical means of distinction, we will discover that the marked indefinite interpretation (in the case of noun-adjective agreement) and definite interpretation (in the case of verb morphology indicating result focus) are preserved in every possible syntactic position of the NP: 
(16) a. Za dver'ju slyšalsya ženskij golos.

behind door was-heard woman-MASC.SG.NOM voice-MASC.SG.NOM

'There was a woman's voice heard from behind the door.'
b. ???Ženskij golos slyšalsya za dver'ju.
woman-MASC.SG.NOM voice-MASC.SG.NOM was-heard behind door
'A woman's voice was heard from behind a/the door.'

(17) a. Pis'mo on dopisal.

letter he has-written-to-the-end-PERF

'The letter he has written to the end.'

b. On dopisal pis'mo.

he has-written-to-the-end-PERF letter.

'He has written the letter to the end.'

If we consider the unmarked counterparts of the sentences in (16\&17), we will see that the interpretation of the NPs becomes marked in some positions in the sentence but remains unmarked in the others:

a. Golos ženščiny slyšalsya za dver'ju.

voice-MASC.SG.NOM woman-FEM.SG.GEN was-heard behind door

'The voice of the woman was heard from behind a/the door.'

b. Za dver'ju slyšalsya golos ženščhiny.

behind door was-heard voice-MASC.SG.NOM woman-FEM.SG.GEN

'The voice of a/the woman was heard from behind the door.'

a. On napisal pis'mo.

he has-written-PERF letter

'He has written a/the letter.'

b. Pis'mo on napisal.

letter he has-written-PERF

'He has written the letter.'

It is obvious from the translations that the preferred interpretation becomes definite in both cases once the unmarked NP is moved to a preverbal position. However, in some cases the indefinite interpretation is still available even if the NP is fronted. These cases are characterized by the NP in question appearing within the focus of the sentence. Following are three examples of such structures:
a. Q: Čto tebya otvlekalo?
what you distracted
'What was distracting you?'

\footnotetext{
5 The reason for the degraded status of example (16b) will be considered later. Previewing the discussion still to follow, this sentence has a non-focused NP with indefinite interpretation in a preverbal position, which is strongly dispreferred in Russian.
} 


\author{
A1: General description \\ Golos žensčiny slyšalsya za dver'ju. \\ voice-MASC.SG.NOM woman-FEM.SG.GEN was-heard behind door \\ 'The voice of a woman was heard from behind a/the door.' \\ A2: Sentence Fragment \\ Golos žensčiny. \\ voice- MASC.SG.NOM wornan- FEM.SG.GEN \\ 'The voice of a woman.' \\ b. PIS'MO on napisal. \\ LETTER he has-written-PERF \\ 'A LETTER he has written.'
}

Example (20a) contains two all-focus sentences as answers to the same question: a general description and a verbless fragment. Example (20b) is a case of an emphatic sentence: the focused NP is focus-marked by the intonational peak. In both cases, the preferred reading for the NPs is indefinite.

\title{
4.3. Interim summary
}

I would like to sum up the observations with respect to the interactions between the syntactic and other ways of denoting (in)definiteness made earlier. First, we have seen that once a NP is marked for definiteness or indefinites by lexical or non-lexical means, its interpretation is not affected by word order effects. In other words, the non-syntactic marking dominates the syntactic one and overrides the effects of word order. The situation is quite different with unmarked NPs: the position within the sentence seems to affect the interpretation of these NPs. In particular, NP fronting results in definite interpretation while the interpretation of postverbal NPs depends on other factors such as context. In any event, no unified analysis of the described behavior of NPs may be offered based exclusively on what was said so far. I propose that the mechanisms behind the interpretation of unmarked NPs are based on the information structure of a Russian sentence provided in section 3 above.

\section{Information structure and the status of NP}

\section{1. (In)definiteness}

Having developed the mechanisms for determining the status of Russian NPs with respect to (in)definiteness, and also having established the articulation for the information structure of this language, we can now determine whether any correlations between the discourse function and definiteness exist. Prior to proceeding with this task, I shall present a definition of (in)definiteness employed in this work:

(21) Definiteness: Determiners bear the morpho-syntactic feature of $+/$-Definite. Definiteness is a purely syntactic notion. 
Note that I assume that all Russian nominals are DPs and that bare (i.e., unmarked) nominals are headed by a phonologically null Determiner which might be specified as [+Definite] or [-Definite].

\subsubsection{Discourse-neutral configurations}

First claim I can make with respect to discourse functions of NPs in Russian is the degrading status of indefinite NPs in non-focus preverbal positions observed earlier:

$$
\begin{aligned}
& \text { ???Vsyakie deti edyat moroženoe. } \\
& \text { any children eat ice-cream } \\
& \text { 'Any children eat ice-cream.' }
\end{aligned}
$$

We now know that in non-emphatic speech, these positions are reserved exclusively for topics or discourse neutral information. As was already observed by many linguists (Vallduví 1992; King 1995, inter al.), topics tend to be expressed by definite NPs (being the source of old and usually already mentioned information). In addition, we may note that neutral information may not be discourse new, as this would put it into the focus category. Instead, neutral nominals correspond to familiar (in the sense of Karttunen [1968]) information that does not represent current concern for the interlocutors. Hence, discourse neutral nominals must be interpreted as definite. Such a prediction is empirically confirmed:

$$
\begin{aligned}
& \text { Q: Kto šil eto plat'je? } \\
& \text { who sewed this dress } \\
& \text { 'Who sewed this dress?' } \\
& \text { A: \#[r Eto plat'je] [NI šila komu-libo] [F portnixa]. } \\
& \text { this dress sewed anyone-DAT tailor } \\
& \text { 'A tailor sewed this dress for anyone.' }
\end{aligned}
$$

However, the observation that only definite nominals may appear in neutral information position is not borne out with respect to topics. Indefinite NPs with specific interpretation (24) and so-called 'partitive specifics' (25) (Enç 1991) are fine as topics (see Cresti 1995 for an in-depth discussion of indefinite topics in English):

(24) Koe-kakaja zvezda pojavilas' na nebe.

some star appeared on sky

'Some (specific) star appeared in the sky.'

(25) Q: Čto delajut deti?

what do children

'What are the children doing?' 

A: [T Kakie-to/koe-kakie deti] [F edyat moroženoe]. some children eat ice-cream 'Some (specific) children are eating ice-cream.'

The observation that indefinite nominals may appear in the topic position is not surprising: cross-linguistically, indefinites may have a specific (i.e., presuppositional) reading (cf. Diesing 1992). Under this reading they refer to a member of a set already established in the universe of discourse and act as generalized quantifiers.

Another type of indefinite NPs that may be found in the topic position is a NP with generic interpretation:

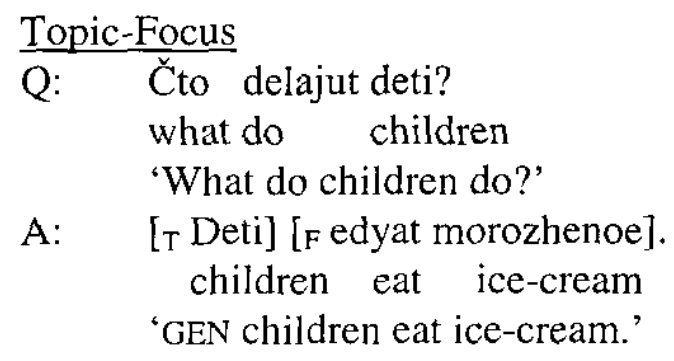

Once again, the NPs with generic interpretation are semantically closer to definite NPs than the ones with existential reading in that they describe an exceptionless set of individuals or items. Hence, for the purposes of information packaging, the NPs with generic interpretation have a characteristic of being specific as their referents are equally easy to be picked out as the particular referents of the definite NPs (see Diesing 1992:16-21 for discussion of generic NPs in English).

Let us now turn to the status of NPs functioning as foci. Consider the following examples:

$$
\begin{aligned}
& \text { All-Focus } \\
& \text { Q: Čto proisxodit? } \\
& \text { what is-happening } \\
& \text { 'What is going on?' } \\
& \text { A1: [F Deti/ kakie-to deti edyat moroženoe]. } \\
& \text { children/some children eat ice-cream } \\
& \text { '(\#The) children eat ice-cream.' } \\
& \text { A2: [F Moi/eti deti edyat moroženoe]. } \\
& \text { my/these children eat ice-cream } \\
& \text { 'My/these children eat ice-cream.' }
\end{aligned}
$$

(28) Neutral Information-Focus

$\begin{array}{ll}\mathrm{Q}: & \text { Kto igraet? } \\ & \text { who plays } \\ & \text { 'Who is playing?' }\end{array}$



A1: [NI Igrajut] [F deti/vsyakie deti]. play children/any children '(\#The) children are playing.'

A2: [NI Igrajut] [F moi/eti deti]. play my/these children 'My/these children are playing.'

These examples indicate that a NP marked as indefinite is grammatical in the focus position. Moreover, the preferred interpretation for noun phrases occurring within focus is indefinite when the NP is unmarked. However, when the NP is marked as definite, either lexically or non-lexically, the focused nominal is interpreted as definite.

\subsubsection{Emphatic Configurations}

In this subsection, I will examine the dependence on discourse position of NPs found in emphatic contexts. Examples in (24) below illustrate the possible distribution patterns:

Q: Za dver'ju slyšalsya laj sobak? behind door was-heard bark dogs

'Was it the barking of dogs that was heard from behind the door?'
A1: ???[F ŽENSKIJ
GOLOS]
za dver'ju slyšalsya! woman-MASC.SG.NOM voice-MASC.SG.NOM behind door was-heard ???Za dver'ju [F ŽENSKIJ GOLOS] slyšalsya!
'It was A WOMAN's VOICE that was heard from behind the door!'
A2: [F GOLOS ŽENŠČINY] za dver'ju slyšalsya! voice-MASC.SG.NOM woman-FEM.SG.GEN behind door was-heard $\mathrm{Za}$ dver'ju [F GOLOS žENŠČINY] slyšalsya!
'It was THE VOICE OF THE WOMAN that was heard behind the door!'

The data show that the preferred reading for the contrastively focused NPs is definite: the indefinite interpretation receives degrading judgement while definite is accepted. As expected, the described distribution is not affected by the position of the focused constituent within the sentence.

Finally, the presence of an intonationally focused NP in the sentence does not affect the interpretation of the topic:
a. [T Mal'čik] [F PIS'MO] dopisal/napisal! boy LETTER has-written/wrote-PERF
'It was THE LETTER that the/\#a boy has finished writing/wrote!'
b. [F PIS'MO] [T mal'čik] dopisal/napisal! LETTER boy has-written/wrote-PERF
'It was the letter that the/\#a boy has finished writing/wrote!'

Independently of whether the topic of the sentence mal'c $i k$ 'the boy' occurs before or after the contrastively focused NP pis'mo 'the letter', the focused nominal is interpreted as 
definite. This behavior is expected since (in)definiteness is associated with the discourse function of the NP rather than with its position with respect to other discourse elements.

\subsubsection{Summary}

Summarizing the discovered correlations between Russian discourse structure and the status of NPs with respect to (in)definiteness, I shall confirm the earlier proposed generalization about the correlation between the position and the interpretation of a nominal. Moreover, such a generalization receives a natural explanation once the information structure of the sentence is invoked. To recapitulate, the interpretation of an unmarked nominal depends on the information structure function it represents: topics, neutral elements, and contrastive foci are definite, while information foci are indefinite. However, overt marking for (in)definiteness overrides the status of NP obtained through information structure. In other words, the effects of lexical marking seem to be stronger than discourse-level effects.

Although the interpretation of unmarked nominals seems to be accounted for through the information structure, an obvious shortcoming of the analysis proposed so far is in the lack of uniformity between the behavior of marked and unmarked nominals. In what follows, I shall consider other possible solutions for this problem.

\subsection{Specificity}

In the previous subsection, I showed that the mapping between information structure and the interpretation of NP is problematic when the notion of (in)definiteness is used as a criterion for the distribution of the NPs. Recall also that main difficulty is caused by the availability of indefinite topics and definite foci. What all types of indefinite topics have in common is the underlying feature of specificity: in order for an indefinite NP to be topicalized, it must have a presuppositional reading. Naturally, the next candidate to consider in order to obtain a straightforward system of correlations is specificity. The definition of specificity used in this paper is given below (cf. Fodor \& Sag 1982, Heim 1982, Runner 1994, Schaeffer 1997):

(31) Specificity: A specific nominal has a fixed referent in (the model of) the world, one that can be identified by the speaker and/or the person whose propositional attitudes are being reported.

The following predictions can be made with respect to the possible correlations between specificity of nominals and information structure:

(i) Both indefinite and definite topics must be specific.

(ii) Contrastive foci must also be specific since they are overwhelmingly expressed by definite NPs and involve known or inferable sets of items.

(iii) Finally, new information foci should be represented by non-specific nominals. 
As was shown earlier in this paper, the first two predictions are borne out. As to the third statement, the following example indicates to the contrary:
Q: Čto proisxodit?
what is-happening
'What is going on?'
A: $\quad$ Ivan/moj syn p'jet vodku.
Ivan/my son drinks vodka
'Ivan/my son is drinking vodka.'

The subject nominals in (32-A) represent the case of novel definites (discussed, for example, by Hawkins [1978] and Heim [1982], inter al.). The referents of such definite NPs are established by means of accommodation (see Clark 1977 and Heim 1982 for detailed discussion of this process) rather than through introduction in the previous discourse. Nevertheless, the referents of novel definites are specific and, since they occur in focus position, cause a problem for the analysis involving the connections between specificity and information structure.

\subsection{D-linking}

We have seen that neither the morpho-syntactic feature of (in)definiteness nor the semantic notion of specificity were sufficient to define the classes of nominals representing certain information structure functions. However, recall that the problem with the new information foci associated with specific reading has to do with the way the referent of the nominal is introduced into the discourse. While the specific referents of novel definite nominals are not introduced through the previous discourse, the specific referents of definite or indefinite nominals are necessarily pre-established in discourse. Such a distinction is provided by the notion of D(iscourse)-linking (Pesetsky 1987).

(33) D-linking: A D-linked nominal has a referent pre-established in the discourse, or a referent belonging to a set pre-established in the discourse. Non-D-linked nominal has a referent new in the discourse or in the utterance.

Note that such a definition requires that the referent of a D-linked element be familiar to both speaker and hearer. Now let us consider the system of correlations between nominals classified with respect to D-linking and the information structure:

(i) All topics must be D-linked since they are either previously mentioned individuals or items, or members of a set previously established in the discourse.

(ii) Contrastive foci must be D-linked since they represent elements familiar or inferable from previous discourse.

(iii) Finally, new information foci are obligatorily non-D-linked since their referents come from sets familiar only to the speaker and, therefore, are new to the hearer. 
I conclude that $\mathrm{D}$-linking may be used as a criterion describing the correlation between information structure and the status of NP in Russian. Such a choice seems to be justified since the nature of the functions of information structure is discourse-motivated. Hence a logical classification of elements representing information structure functions has to be discourse-based rather than be defined according to semantic or syntactic features.

\section{Conclusions}

In this paper, I have established that Russian NPs can be overtly marked as (in)definite, or alternatively appear unmarked for this feature. The status of unmarked NPs is determined based on the function of information structure it represents.

I also showed that the notion of (in)definiteness is not sufficient to provide a logical system of co-dependencies between the functions of information structure and the status of NP, both marked and unmarked. Instead, I proposed that the classification of nominals with respect to information structure be based on D-linking (Pesetsky 1987). D-linking, a tool of the syntax-discourse interface, appears to be a natural candidate for the connection between information structure and the referential status of a nominal.

Finally, topics for further research include an investigation of the mechanisms of Dlinking with respect to information packaging in a wider range of languages demonstrating free word order and lack of obligatory overt marking for (in)definiteness. In addition, the development of a more structural analysis of the syntax-discourse interface accounting for the facts described in this paper is needed.

\section{References}

Adamec, P. (1966). Poryadok slov v sovremennom russkom jazyke (Word order in Modern Russian.) In Rozpravy Ceskoslovenske Akademie Ved, Rada spolecenskych ved 76.

Apresyan, Y. D. (1995). Leksicheskaja semantika: sinonimicheskie sredstava jazyka (Lexical Semantics: Synonimical Mechanisms of a Language.) Moscow: Yazyki Russkoj Kul'tury.

Brun, D. (2000). Discourse structure and definiteness in Russian. In C. Czinglar, K. Köhler, E. Thrift, E. J. van der Torre, \& M. Zimmermann (eds.), Proceedings of ConSOLE 8, Vienna, Austria: 45-61.

Bryzgunova, E. (1971). O smyslorazlichitel'nyh vozmoznostyah russkoj intonatsii (On the meaningdistinguishing potential of Russian intonation.) Voprosy jazykoznanija 4, 42-51.

Bryzgunova, E. (1981). Zvuk I intontsija russkoj rechi (Sound and Intonation of Russian speech.) Moscow: Russkij Yazyk.

Chomsky, N. (1991). Some notes on the economy of derivation. In Freidin (ed.), Principles and Parameters in Comparative Grammar, 417-454.

Chomsky, N. (1992). A Minimalist Program for Linguistic Theory, MIT Occasional Papers in Linguistics, Cambridge, MA: The MIT Press.

Chvany, C. (1973). Notes on 'Root' and 'Structure-Preserving' in Russian. In Corum, C., T. C. Smith-Stark \& A. Weiser (eds.), You Take the High Node and I'll Take the Low Node, 252-290, Chicago, IL: Chicago Linguistic Society.

Clark, H. (1977). Bridging. In Johnson-Laird, P. \& P. Wason (eds.), Thinking. Cambridge University Press, Cambridge: $411-420$.

Cresti, D. (1995). Indefinite Topics. Ph.D. dissertation, MIT. 
Diesing, M. (1992). Indefinites. Cambridge, MA: The MIT Press.

Enç, M. (1991). The Semantics of Specificity. Linguistic Inquiry 22:1-25.

Firbas, J. (1964). From comparative word-order studies. Brno Studies in English 4:111-128.

Firbas, J. (1965). A note on transition proper in functional sentence analysis. Philologica Pragensia 8: 170 176.

Firbas, J. (1966). On Defining Theme in Functional Sentence Analysis. TraLing 2.

Fodor, J. D. \& I. A. Sag. (1982). Referential and Quantificational Indefinites. Linguistics and Philosophy 5, 355-398.

Hajičová, E. (1974). Meaning, presupposition, and allegation. Philologica Pragensia 17: 18-25.

Hawkins, J. (1978). Definiteness and Indefiniteness. London: Croom Helm.

Heim, I. (1982). The semantics of definite and indefinite noun phrases. Ph.D. dissertation, UMASS.

Isačenko, A. (1966). O grammaticeskom porjadke slov. Voprosy jazykoznanija 6: 27-34.

Junghanns, U. \& G. Zybatow (1995). Syntax and information structure of Russian clauses. Proceedings of FASL 3, Cornell University.

Karttunen, L. (1968). What Do Referential Indices Refer to? Rand Corporation Publication, Santa Monica, CA.

King, T. H. (1995). Configuring Topic and Focus in Russian. Stanford, CA: CSLI Publications.

Kiss, E. K. (1993). Genericity, predication, and focus. Ms., Stanford University.

Krylova, O. \& S. Khavronina (1988). Word order in Russian. Moscow: Russkij Yazyk.

Mathesius, V. (1964). On some problems of the systematic analysis of grammar. In Vachek, J. (ed.), A Prague School Reader in Linguistics, 306-319. Bloomington, IN: Indiana University Press.

Pesetsky, D. (1987) Wh-in situ: movement and unselective binding. In E reuland and A. ter Meulen (eds.), The Representation of (In)definiteness. Cambridge, MA: MIT Press.

Prince, E. (1981). Toward a taxonomy of given-new information. In Cole, P. (ed.), Radical Pragmatics, 223256. New York, NY: Academic Press.

Rochemont, M. (1986). Focus in Generative Grammar. Amsterdam, Holland: John Benjamins.

Runner, J. (1994). A specific role for AGR. In E. Benedicto \& J. Runner (eds.), Functional Projections, UMass (Amherst) Occasional Papers \# 17: 153-177.

Schaeffer, I. (1997). Direct object scrambling in Dutch and Italian child language. Ph.D. dissertation. UCLA.

Sgall, P. (1972). Topic, focus, and the ordering of elements of semantic representations. Philologica Pragensia 15: 1-14.

Sgall, P., E. Hajičová \& J. Panevova. (1986). The Meaning of the Sentence in Its Semantic and Pragmatic Aspects. Dordrecht, Holland: Reidel.

Vallduví, E. (1992). The Informational Component. New York, NY: Garland.

Yokoyama, O. (1986). Discourse and Word Order. Amsterdam, Holland: John Benjamins. 